\title{
UMA DOR ALÉM DO PARTO: VIOLÊNCIA OBSTÉTRICA EM FOCO
}

\section{A PAIN BEYOND CHILDBIRTH: OBSTETRICAL VIOLENCE IN FOCUS}

\author{
${ }^{1}$ Artenira da Silva e Silva Sauaia \\ ${ }^{2}$ Maiane Cibele de Mesquita Serra
}

\section{RESUMO}

A violência obstétrica é uma forma de violência de gênero e implica em violação de direitos humanos, caracterizada pela imposição de intervenções danosas à integridade física e psicológica das parturientes, perpetrada pelos profissionais de saúde, bem como pelas instituições (públicas e privadas) nas quais tais mulheres são atendidas. Desta forma, o presente artigo possui como finalidade discutir a violência obstétrica, bem como sua caracterização, a partir da análise dos acórdãos do Supremo Tribunal Federal (STF) e Superior Tribunal de Justiça (STJ). Foram selecionados e discutidos os julgados que mais evidenciavam a temática abordada.

Palavras-chave: Violência obstétrica, Parturientes, Direitos, Mulheres

\begin{abstract}
Obstetric violence is a type of gender violence and it implies violation of human rights, characterized by the imposition of harmful interventions to the physical and psychological integrity of pregnant women, perpetrated by health professionals and institutions (public and private) in which such women are assisted. Thus, this paper has as the purpose to discuss obstetric violence as well as its characterization through the judgments of the Supreme Federal Court (STF) and the Superior Court of Justice (STJ). The judgments with more evidence about the theme were selected and discussed.
\end{abstract}

Keywords: Obstetric violence, Parturients, Rights, Women

\footnotetext{
${ }^{1}$ Pós-Doutora em Psicologia e Educação pela Universidade do Porto - U.PORTO, Portugal. Docente, Pesquisadora, Coordenadora Política de Internacionalização na Universidade Federal do Maranhão - UFMA, São Luís, Maranhão. E-mail: tutortreinamento@gmail.com

${ }^{2}$ Mestranda em Direito e Instituições do Sistema de Justiça, do Programa de Pós-Graduação em Direito da Universidade Federal do Maranhão - UFMA. Advogada pela OAB/MA. E-mail: tutortreinamento@gmail.com
} 


\section{INTRODUÇÃO}

A violência é um problema social que está em constante processo de expansão em todas as suas formas. A violência contra a mulher, em especial, é um problema do Estado, uma vez que é uma das violações mais frequentes dos direitos humanos e constitui-se como um problema de saúde pública que gera custos econômicos e sociais elevados. Tal modalidade de violência tem perdurado ao longo da história e na atualidade ganhou caráter endêmico, uma vez que está cotidianamente presente nas comunidades e países de todo o mundo, independentemente da classe social, raça, idade, sexo ou religião. (FONEITE; FEU; MERLO, 2012).

A Organização Mundial de Saúde (OMS) define violência como a imposição de um grau significativo de dor e sofrimento evitáveis. Por sua vez, a violência contra a mulher é definida pela Convenção Interamericana para Prevenir, Punir e Erradicar a Violência contra a Mulher, também conhecida como "Convenção de Belém do Pará", no seu art. $1^{\text {o }}$ como: "qualquer ato ou conduta baseada no gênero, que cause morte, dano ou sofrimento físico, sexual ou psicológico à mulher, tanto na esfera pública como na esfera privada”. E no art. $6^{\circ}$ determina que o direito de toda mulher a ser livre de violência, abrange, entre outros, o direito a ser livre de todas as formas de discriminação, além do direito de ser valorizada e educada livre de padrões estereotipados de comportamento e costumes sociais e culturais baseados em conceitos de inferioridade ou subordinação.

No que tange à violência de gênero podemos considerar as violências física, sexual e psicológica ocorridas tanto no âmbito privado quanto público, e podendo ser perpetradas inclusive pelo Estado e seus agentes. Tal tipo de violência manifesta-se por meio das relações de poder, histórica e culturalmente desiguais, ocorridas entre homens e mulheres.

A violência obstétrica corresponde a uma forma específica da violência de gênero, uma vez que há utilização arbitrária do saber por parte de profissionais da saúde no controle dos corpos e da sexualidade das parturientes.

Esta modalidade de violência caracteriza-se pela apropriação do corpo e dos processos reprodutivos da mulher pelos agentes de saúde, mediante um tratamento desumanizado, abuso de medicalização e patologização dos processos naturais, causando a perda de autonomia da parturiente e da sua capacidade de decidir livremente sobre seu corpo e sexualidade, o que pode culminar com consequências negativas e desastrosas para a qualidade de vida das mulheres ${ }^{1}$.

\footnotetext{
${ }^{1}$ Definição dada pelas leis venezuela e argentina, onde a violência obstétrica é tipificada.
} 
A parturiente, como sujeito de direitos possui uma série de prerrogativas: a dignidade da pessoa humana (art. $1^{\circ}$, III, CRFB/88) como fundamento do Estado Democrático de Direito; o princípio da igualdade (art. $5^{\circ}, \mathrm{I}, \mathrm{CRFB} / 88$ ) que a protege de todas as formas de discriminação; o princípio da legalidade (art. $5^{\circ}, \mathrm{II}, \mathrm{CRFB} / 88$ ) que assegura autonomia à mulher; e ainda a proteção à vida, à saúde (acesso, segurança), à maternidade e à infância (Princípio da Beneficência).

Entretanto, tais direitos e prerrogativas têm sido amplamente desrespeitados. Destarte, este estudo se justifica pela relevância social e jurídica da temática, uma vez que consoante pesquisa realizada pela Fundação Perseu Abramo, uma em cada quatro mulheres sofre violência obstétrica.

A fim de tornar mais objetiva a reflexão proposta, foram analisados acórdãos do Supremo Tribunal Federal (STF) e Superior Tribunal de Justiça (STJ), no intuito de verificar se as decisões proferidas poderiam ser utilizadas para observância da violência obstétrica e se consequentemente poderiam funcionar como paradigma para solucionar casos análogos no que tange à temática, além de buscar dar efetiva visibilidade ao tema. A pesquisa foi feita nos próprios sítios eletrônicos dos respectivos tribunais nos meses de outubro e novembro de 2015 através de uma busca exploratória de palavras-chave correlacionadas às práticas de violência obstétrica. Após análise de cada acórdão encontrado, foram selecionados três julgados que mais evidenciaram a problemática.

\section{O CENÁRIO BRASILEIRO DO PARTO: REFLEXÕES GERAIS ACERCA DA VIOLÊNCIA OBSTÉTRICA}

O cenário brasileiro no que diz respeito ao parto é alarmante quando observado sob a ótica dos partos cesáreas ${ }^{2}$. A partir de dados atuais $(2015)^{3}$, a OMS concluiu que as taxas de cesáreas são efetivas para salvar vidas de mães e crianças, quando indicadas ao caso e feitas em um ambiente seguro, mas faz alertas sobre os seus riscos.

Os índices alarmantes de cesáreas estão intrinsicamente relacionados a ideações culturais introjetadas a partir das quais o parto cesariano é uma forma mais moderna e higiênica de parto, sendo uma escolha para as gestantes que têm maior poder aquisitivo, enquanto o parto normal é tido como feio, primitivo e sujo, realizado apenas com as que não

\footnotetext{
${ }^{2}$ As cesarianas somam um índice de $84,6 \%$ na rede pública hospitalar e $40 \%$ na rede particular, segundo dados do Ministério da Saúde, fazendo do Brasil, líder mundial nesta modalidade de parto e dando ensejo à chamada "epidemia das cesáreas".

${ }^{3}$ Declaração da OMS sobre Taxas de Cesáreas.
} 
possuem condições de arcar com os custos vultuosos de uma cesariana, conforme bem expressa Simone Dias, do Departamento de Saúde Pública da Universidade de São Paulo (USP).

Além disso, um dos fatores que mais influem para configurar esta problemática é o fato do parto normal ser um processo doloroso e arriscado no Brasil, gerando sofrimento à parturiente. Conforme ainda a pesquisadora, o parto normal com conotação violenta é constantemente utilizado para vender cesárea, desta forma, esta modalidade de parto se torna a melhor alternativa para escapar desse cenário comumente iatrogênico.

\begin{abstract}
No parto vaginal a violência da imposição de rotinas, da posição de parto e das interferências obstétricas desnecessárias perturbam e inibem o desencadeamento natural dos mecanismos fisiológicos do parto, que passa a ser sinônimo de patologia e de intervenção médica, transformando-se em uma experiência de terror, impotência, alienação e dor. Desta forma, não surpreende que as mulheres introjetem a cesárea como melhor forma de dar à luz, sem medo, sem risco e sem dor. (DINIZ, 2005, p. 231).
\end{abstract}

Assim, o excesso de realização de cesáreas no país pode estar ligado a fatores inerentes à violência obstétrica e a questões culturais. Tal modalidade de violência, também conhecida como violência institucional na atenção obstétrica caracteriza-se pela:

[...] violência cometida contra a mulher grávida, e sua família em serviços de saúde durante a assistência ao pré-natal, parto, pós-parto, cesárea e abortamento. Pode ser verbal, física, psicológica ou mesmo sexual e se expressa de diversas maneiras explícitas ou veladas. Como outras formas de violência contra a mulher, a violência obstétrica é fortemente condicionada por preconceitos de gênero. (PARTO DO PRINCÍPIO, 2014, p. 11).

Evidencia-se ainda, pela imposição de intervenções que são danosas, prejudicando tanto a integridade física quanto psíquica da mulher, desrespeitando a autonomia da parturiente. Segundo a OMS, muitas das intervenções que são aplicadas rotineiramente são consideradas como um fator de risco tanto para a mulher quanto para o neonato. Ademais, as crenças e os preconceitos no que concerne à sexualidade e saúde das mulheres numa sociedade tipicamente patriarcal contribuem sobremaneira diante da forma como elas são vistas e des(tratadas) pelos profissionais.

Diante do exposto, acreditamos que a violência obstétrica corresponde a uma forma específica de violência de gênero, uma vez que diversas pesquisas (MCCALLUM E REIS, 2006; RICHARD ET AL., 2003; HOTIMSKY, 2002, 2007; ET AL., 2002; HOGA ET AL., 2002; CLADEM \& CRLP,1998, apud AGUIAR, 2010, p. 14) apontam que a utilização 
arbitrária do saber por parte de profissionais da saúde no controle dos corpos e da sexualidade de suas pacientes é uma das principais formas dessa violência institucional.

Consoante Aguiar:

\begin{abstract}
Estes maus tratos vividos pelas pacientes, na maioria das vezes, segundo alguns autores, encontram-se relacionados a práticas discriminatórias por parte dos profissionais, quanto a gênero, entrelaçados com discriminação de classe social e etnia, subjacentes à permanência de uma ideologia que naturaliza a condição social de reprodutora da mulher como seu destino biológico, e marca uma inferioridade física e moral da mulher que permite que seu corpo e sua sexualidade sejam objetos de controle da sociedade através da prática médica (2010, p. 15).
\end{abstract}

O sistema jurídico brasileiro não possui legislação específica sobre a temática, apenas abordagem genérica. Entretanto, existe o Projeto de Lei 7.633/2014, em tramitação no Congresso Nacional que dispõe sobre a humanização da assistência à mulher e ao neonato durante o ciclo gravídico-puerperal e dá outras providências. Elaborado pela Artemis que atua na defesa e promoção dos direitos das mulheres e assinado pelo deputado Jean Wyllys PSOL/RJ, o projeto foca a questão do parto humanizado frente à prática indiscriminada de cirurgias cesarianas, visando mantê-las no percentual de $15 \%$ recomendado pela OMS.

Em distintas partes do mundo, essa modalidade de violência tem se alastrado de maneira preocupante e silenciosa, haja vista que as mulheres vítimas desta prática não a percebem como tal. Por questões culturais, o parto ainda é encarado como um momento de "dor necessária”. Em algumas situações, quando a parturiente se dá conta da violência praticada contra ela, opta pelo silêncio, muitas vezes pelo medo de ser abandonada pelo profissional em um momento onde está altamente vulnerável ou ainda por não se sentir apoiada quanto à denúncia. Outros fatores contribuem ainda para que a mulher violentada não denuncie a prática, a saber, crer que não possui provas suficientes do ato de violência sofrido; desacreditar na justiça e ainda por desconhecer as atitudes que se configuram como violência obstétrica.

No segundo semestre de 2014, a OMS novamente se pronunciou a respeito da temática, publicando em seis idiomas uma declaração acerca da violência obstétrica, exigindo políticas e promoção à assistência obstétrica humanizada, além da adoção de medidas governamentais no sentido de abolir o desrespeito e abuso contra as mulheres durante o parto.

Segundo a organização:

Todas as mulheres têm direito ao mais alto padrão de saúde atingível, incluindo o direito a uma assistência digna e respeitosa durante toda a gravidez e o parto, assim como o direito de estar livre da violência e discriminação. Os abusos, os maustratos, a negligência e o desrespeito durante o parto equivalem a uma violação dos 
direitos humanos fundamentais das mulheres, como descrevem as normas e princípios de direitos humanos adotados internacionalmente. Em especial, as mulheres grávidas têm o direito de serem iguais em dignidade, de serem livres para procurar, receber e dar informações, de não sofrerem discriminações e de usufruírem do mais alto padrão de saúde física e mental, incluindo a saúde sexual e reprodutiva. (OMS, 2014, p. 01).

Infelizmente, o caso Alyne Pimentel ${ }^{4}$ não é um acontecimento isolado da realidade brasileira. Cotidianamente, mulheres sofrem violência no parto de diversas formas, podendo ocorrer durante o pré-natal, no parto e inclusive em situações de abortamento. A violência obstétrica frequentemente culmina com danos físicos, psicológicos e sexuais em forma de violência institucional contra mulheres.

Durante a gestação a violência obstétrica pode ser caracterizada por: negar atendimento à mulher ou ainda impor alguma dificuldade ao atendimento em postos de saúde onde são realizados o acompanhamento pré-natal; qualquer espécie de comentários constrangedores à mulher e relacionados à sua cor, raça, etnia, idade, escolaridade, religião ou crença, condição econômica, estado civil ou situação conjugal, orientação sexual, número de filhos, etc; ofender, humilhar ou xingar a mulher ou sua família; negligenciar atendimento de qualidade; agendar cesárea sem recomendação baseada em evidências científicas, atendendo simplesmente aos interesses e conveniência do médico. (DEFESORIA PÚBLICA DO ESTADO DE SÃO PAULO, 2013).

Durante o parto, as formas mais comuns deste tipo de violência são: a recusa de admissão em hospital ou maternidade, gerando a chamada peregrinação por leito; impedimento da entrada do acompanhante escolhido pela mulher; aplicação de soro com ocitocina para acelerar o trabalho de parto; episiotomia de rotina; manobra de Kristeller; cesáreas eletivas; restrição da posição do parto; violência psicológica; impedir ou retardar o contato do bebê com a mulher logo após o trabalho de parto; impedir o alojamento conjunto da mãe e o neonato; impedir ou dificultar o aleitamento materno; além de outros procedimentos dolorosos, desnecessários e humilhantes, tais como: uso rotineiro de lavagem intestinal (enema), retirada dos pelos pubianos (tricotomia), posição ginecológica com portas abertas, exames de toque sucessivos e por pessoas diferentes para verificar a dilatação, privação de alimentos e água, imobilização de braços e pernas, etc.

Nos casos de abortamento, a violência caracteriza-se por: negativa ou demora no atendimento à mulher em situação de abortamento; questionamento à mulher quanto à causa

\footnotetext{
4 Primeira condenação internacional referente à morte materna, o caso foi levado ao Comitê CEDAW (Convenção sobre a Eliminação de todas as Formas de Discriminação contra a Mulher) da ONU em 2011, onde o Brasil foi condenado ao pagamento de indenização por negligência no serviço público de saúde.
} 
do abortamento (se foi intencional ou não); realização de procedimentos predominantemente invasivos, sem explicação, consentimento e frequentemente sem anestesia; ameaças, acusação e culpabilização da mulher; coação com finalidade de confissão e denúncia. (DEFESORIA PÚBLICA DO ESTADO DE SÃO PAULO, 2013).

\title{
2.1 Episiotomia
}

\begin{abstract}
Quando eu ouvi ele pedindo o bisturi, meu Deus, quase morri! Eu pedi para que não fizesse a episio, mas ele me respondeu: 'O seguro morreu de velho. Quem manda aqui sou eu. (PARTO DO PRINCÍPIO, 2012, p. 83).
\end{abstract}

\begin{abstract}
Minha cicatriz ficou maior ainda na minha alma. Me senti violentada, me senti punida, me senti menos feminina, como se por ser mãe, precisasse ser marcada nessa vida de gado. [...] Chorei muito, sentia dor, vergonha da minha perereca com cicatriz, vergonha de estar ligando para isso, sentia medo, medo de não consegui mais transar. Tenho pavor de cortes, tinha medo de que o corte abrisse quando fosse transar. Demorei uns cinco meses para voltar a transar mais ou menos relaxada, sentia dores, chorava quando começava, parava. Me sentia roubada, me tinham roubado minha sexualidade, minha autoestima, me sentia castrada. (PARTO DO PRINCÍPIO, 2012, p. 83).
\end{abstract}

A episiotomia caracteriza-se por um procedimento cirúrgico realizado pelos médicos para aumentar a abertura do canal vaginal com uma incisão realizada na vulva, cortando a entrada da vagina com uma tesoura ou bisturi, algumas vezes sem anestesia. A cirurgia afeta diversas estruturas do períneo, tais como os músculos, vasos sanguíneos e tendões, gerando em alguns casos, incontinência urinária e fecal, além de provocar outras complicações, dentre elas a dor nas relações sexuais, risco de infecção e laceração perineal em partos subsequentes, maior volume de sangramento, além dos resultados estéticos insatisfatórios. (PREVIATTI; SOUZA, 2007).

Diante do cenário, Previatti e Souza postulam que:

É fato que a episiotomia vem sendo utilizada de forma indiscriminada na assistência obstétrica. É fato também que, os profissionais de saúde arraigados a conceitos e práticas que não contemplam os resultados de evidências científicas atuais, bem como, as práticas baseadas nos direitos das mulheres, insistem na realização deste procedimento, mantêm um enfoque intervencionista e assim subtraem da mulherparturiente a possibilidade de experienciar o parto, como um processo fisiológico e fortalecedor de sua autonomia. (2007, p. 198).

Relatos como os expressos anteriormente, mostram a triste e constante realidade de mulheres que são submetidas a episiotomia de rotina. É a única cirurgia do Brasil, realizada sem o consentimento da paciente e sem tampouco a informação sobre os riscos, possíveis benefícios e efeitos adversos. (PARTO DO PRINCÍPIO, 2012). 
A pesquisa "Nascer no Brasil" estima que a episiotomia seja realizada em 53,5\% dos partos via vaginal no Brasil, enquanto a recomendação da OMS é que seja realizada em 10\% deles. No caso de primíparas (primeiro filho), o índice chega a 74\%. Apesar de ser uma prática comum no cenário obstétrico, salienta-se que o procedimento foi introduzido na rotina obstétrica sem qualquer evidência científica sobre sua efetividade, razão pela qual se pretende torná-la uma técnica restrita e não mais rotineira em obstetrícia. (ALEXANDRE et al., 2009).

Conforme Diniz (2003) o uso indevido da episiotomia e da posterior costura (episiorrafia) é um exemplo de violação do direito humano de estar livre de tratamentos cruéis, humilhantes e degradantes. Desta forma, na fala dos profissionais, repete-se constantemente a crença de que sem a sutura adicional conhecida como "ponto do marido", o parceiro se desinteressaria sexualmente pela mulher.

\title{
2.2 Manobra de Kristeller
}

\begin{abstract}
A médica gritava comigo, me mandava ficar quieta. Em um momento, ela pediu para um acadêmico, ele, bem forte, colocou uma mão no início do meu estômago e a outra no final da barriga e empurrou. Senti o corpinho da minha filha saindo. Quando ela nasceu, eu estava tão fragilizada que nem consegui chorar. Ficou o trauma do hospital. Até hoje, quando passo por lá, me vêm as lembranças. (TORRE, 2014).
\end{abstract}

A manobra de Kristeller é usada com frequência nos hospitais com a finalidade de acelerar a expulsão do feto. Consiste em uma manobra na parte superior do útero, durante as contrações do parto, visando empurrar o nascituro em direção à pelve. Utiliza-se as mãos, braço, antebraço, joelho, e em casos mais absurdos as pessoas sobem em cima do abdômen da parturiente.

O fato consiste num flagrante desrespeito à integridade física e nos casos mais comuns pode provocar: lesão dos órgãos internos, hematomas, fratura de costelas, hemorragias e contusões e além disso gera violência psicológica à gestante. Ademais, expõe a criança ao aumento da probabilidade de complicações decorrentes de distócia de ombros, fratura de clavícula, trauma encefálico, descolamento do músculo esternocleidomastoideo ${ }^{5}$, hipóxia ${ }^{6}$, etc.

\subsection{Aplicação de Ocitocina}

\footnotetext{
${ }^{5}$ É um músculo da face lateral do pescoço, na região anterolateral. É o principal flexor do pescoço.

${ }^{6}$ Sofrimento para o feto com diminuição ou ausência de oxigênio necessário ao feto por meio da placenta.
} 
A enfermeira disse que, como eu estava "quase lá", ela colocaria o "sorinho" em mim primeiro. Perguntei o que tinha no soro e ela falou que tinha ocitocina. Eu disse NÃO. Ela não deu importância. Pelo contrário, disse que ia me colocar, porque ninguém ali queria um bebê morto, não é mesmo? As pessoas vão para o Hospital para ter um bebê vivo, e se eu tivesse que ir para a UTI ninguém perderia tempo achando minha veia. Ainda reclamou que a veia da minha mão era muito torta. (PARTO DO PRINCÍPIO, 2012, p. 138).

A ocitocina é um hormônio que acelera o processo de contrações uterinas acelerando o trabalho de parto, entretanto, o próprio corpo se encarrega de produzi-lo. A ocitocina sintética (artificial) usada de maneira indiscriminada, apenas para acelerar o trabalho de parto, sem indicação correta, aplicada no soro da parturiente, causa o aumento significativo das dores durante as contrações e, se não for controlada pode causar sérias complicações para à mulher e o neonato, podendo levar desde a dor e sofrimento desnecessários ao aumento excessivo da frequência cardíaca da parturiente, além de causar dificuldades na oxigenação do bebê, bem como dano cerebral ao mesmo.

\subsection{Cesáreas Eletivas}

Queria o parto normal, mas na primeira consulta, o médico aconselhou cesárea. Entrei em trabalho de parto às 7 horas. Às 3 horas da manhã do dia seguinte, comecei a sangrar e fomos para o hospital. Já estava com 7 centímetros de dilatação. No hospital, urrando de dor, a médica me colocou deitada de barriga para cima, a dor era absurda. Eu pedia para trocar de posição e ela dizia: 'não vou pegar neném nenhum do chão. Se você parir, vai parir deitadinha, de perninha aberta e barriguinha para cima'. Ela fez o exame e disse que o neném estava com batimentos lentos e em sofrimento fetal e que eu teria que fazer cesárea. Eu pedi analgesia, mas ela negou e me disse que eu iria para o centro cirúrgico. Parecia que o que eu falava não era nada. Ela disse a meu marido que eu e meu bebê íamos morrer. Então, fomos para o centro cirúrgico. Fui chorando até lá. Quando meu filho nasceu, não me deixaram encostar nele. Ele nasceu saudável, não precisou de UTI, ele não estava em sofrimento fetal. Sinto frustração. A médica não me deu chance. (TORRE, 2014).

Em geral, a cesariana é indicada quando o trabalho de parto é contraindicado ou quando não é provável que o parto vaginal seja alcançado com segurança, em intervalo de tempo necessário e seguro a fim de prevenir o desenvolvimento de morbidade fetal e/ou materna. (BRASIL, 2008).

Por si tratar de uma intervenção cirúrgica, a cesárea por si só, oferece riscos tanto à parturiente quanto ao neonato. Pode implicar em complicações maternas menores como episódios de febre ou perda maior do volume de sangue, até eventos maiores, tais como, lacerações acidentais de vísceras, infecções puerperais e acidentes anestésicos, razão pela qual 
as evidências médicas indicam que as taxas de mortalidade materna em decorrência de cesárea são até sete vezes maiores do que nos partos normais. (BRASIL, 2008).

A cesárea eletiva é aquela realizada sem necessidade clínica, podendo ser agendada e feita conforme a conveniência médica, antes mesmo do início do trabalho de parto, dissuadindo muitas vezes a mulher quanto à sua necessidade e também a coagindo.

Conforme Maia:

\begin{abstract}
Diversas foram as causas relacionadas a esse evento: [...] medo, por parte das mulheres, da dor do parto normal; crença, por parte das mulheres e dos médicos, de que o parto vaginal afrouxa os músculos da vagina e interfere na satisfação sexual; crença de que o parto vaginal é mais arriscado para o bebê do que uma cesárea; conveniência (hora marcada) e economia de tempo para o médico; falta de qualificação do médico para o parto normal; pré-natal incapaz de preparar para o parto; atendimento centrado no médico, e não em equipes multidisciplinares que incluam obstetrizes ${ }^{7} ;$ [...] a associação entre parto vaginal e imprevisibilidade, esta vista como algo negativo, e entre parto cesáreo e segurança. (2008, p. 38 apud FAÚNDES; CECATTI, 1991; CHACHAM; PERPÉTUO, 1996).
\end{abstract}

Em virtude da falta de informações, as parturientes ficam extremamente vulneráveis às indicações de cesáreas, submetendo-se, na maioria dos casos, a uma cirurgia de grande porte com riscos e complicações.

\title{
2.5 Restrição da Posição para o Parto
}

Perguntei ao meu médico se eu podia escolher a posição para o parto, por exemplo de cócoras. Ele riu e falou que é pra eu tirar essas ideias de 'parto hippie' da cabeça. Eu insisti e ele disse que não estudou tanto para ficar agachado igual a um mecânico. (PARTO DO PRINCÍPIO, 2012, p. 107).

A restrição da posição para o parto conforme a preferência da mulher constitui-se como uma das formas mais frequentes de violência obstétrica. O uso rotineiro da posição de litotomia ${ }^{8}$ com ou sem estribos, prejudica a dinâmica do parto, é desconfortável para muitas gestantes e pode dificultar a oxigenação do neonato.

Sobre a temática, Maia salienta que:

Com a mulher deitada na cama, de pernas para cima e abertas, fica claro que o sujeito do parto é o médico, e não a mulher. Além disso, a litotomia dificulta o trabalho de parto, o que acaba por justificar o uso indiscriminado de ocitocina (soro que acelera as contrações). A posição deitada e a ocitocina prendem a mulher ao

\footnotetext{
${ }^{7}$ São profissionais preparadas para o acompanhamento de gestações, partos e pós-parto de risco habitual ou baixo risco, de forma autônoma ou vinculada a equipe multiprofissional ou instituições de saúde e encaminhamento dos partos/gestações de alto risco para centros especializados.

${ }^{8}$ Posição onde o corpo está deitado com a face voltada para cima, joelho e quadril flexionado a $90^{\circ}$, expondo o períneo.
} 
leito e impedem que ela se movimente livremente, o que, por sua vez, aumenta as dores, justificando a anestesia. A posição deitada e a anestesia a impedem de participar ativamente do parto, obrigando o médico a realizar a manobra de Kristeller (empurrar a barriga da gestante com o braço ou o corpo, manobra banida dos livros de obstetrícia por ser considerada arriscada, mas ainda largamente utilizada). Por fim, a posição deitada não facilita o relaxamento do músculo do períneo, obrigando o médico a realizar a episiotomia em todos os partos vaginais. (2008, p. 36 apud DINIZ; DUARTE, 2004).

Em observância a tal direito da parturiente, a Resolução da Diretoria Colegiada (RDC) 36 de 2008 da Agência Nacional de Vigilância Sanitária (ANVISA) que dispõe sobre o Regulamento Técnico para Funcionamento dos Serviços de Atenção Obstétrica e Neonatal, assegura à gestante "condições de escolha das diversas posições durante o parto, desde que não existam impedimentos clínicos" (2008, p. 07).

\title{
2.6 Proibição do Acompanhante
}

\begin{abstract}
Quando o médico chegou, pedi para deixar o meu marido entrar. Ele não quis deixar, mas meu marido estava com o papel da Lei que permite acompanhante no parto e ele mostrou para o médico. O médico se virou para o meu marido e disse 'Então eu vou embora e você faz o parto. (PARTO DO PRINCÍPIO, 2012, p. 65).
\end{abstract}

A proibição do acompanhante é caracterizada como outra forma de violência obstétrica e descumpre a Lei 11.108/2005; a RDC n 36/2008 da ANVISA que dispõe sobre Regulamento Técnico para Funcionamento dos Serviços de Atenção Obstétrica e Neonatal; além do Estatuto da Criança e do Adolescente (nos casos de adolescentes grávidas).

A Lei 11.108/2005 instituiu aos serviços de saúde do SUS, rede própria ou conveniada, obrigatoriedade em permitir a presença, junto à parturiente, de um acompanhante durante todo o trabalho de parto, parto e pós-parto imediato, sendo, o acompanhante, indicado pela gestante.

A pesquisa Nascer no Brasil realizada pela Escola Nacional de Saúde Pública Sergio Arouca (Ensp/Fiocruz), mostra que menos de 20\% das mulheres se beneficiam da presença contínua do acompanhante durante todo o período de internação, sendo esse ainda um privilégio das mulheres com maior renda e escolaridade, brancas, usuárias do setor privado e que tiveram cesarianas como opção de parto.

\subsection{Violência Psicológica}




\begin{abstract}
O médico entrou e falou 'Vamos fazer esse bebê nascer'. Mandaram eu fazer força, mas não conseguia por causa do quadro de pressão alta. O médico disse que eu seria a primeira mulher do mundo que não ia conseguir parir um filho. Uma enfermeira debochou, disse que 'na hora de fazer foi bom'. Comecei a pedir desculpas, me sentia culpada. 'Seu bebê vai morrer', o médico dizia. Três enfermeiras empurraram minha barriga, e ele nasceu em silêncio. (POMPEO, 2014).
\end{abstract}

Durante um exame de toque, eu pedi para parar pois estava sentindo muita dor. O médico disse: "na hora de fazer tava gostoso, né?". Nessa hora me senti abusada. (PARTO DO PRINCÍPIO, 2012, p. 101).

Duas profissionais relataram, uma médica e uma enfermeira, que um colega na hora de fazer um exame de toque em uma paciente, fazia brincadeiras como 'duvido que você reclame do seu marido' e 'Não está gostoso? (DIP, 2013).

A violência psicológica é uma forma ainda invisibilizada e cruel de agressão contra a mulher e uma das mais recorrentes no ambiente médico-hospitalar. A violência obstétrica psicológica caracteriza-se por: a) privação de informações à parturiente acerca dos procedimentos realizados; b) realização de comentários ofensivos, insultuosos, discriminatórios, humilhantes ou vexatórios; c) tratar a parturiente de forma grosseira, agressiva, não empática e zombeteira; d) expor a parturiente a situações de medo, abandono, inferioridade ou insegurança; e) recriminação pelos comportamentos da parturiente, proibindo-a de expressar suas dores e/ou emoções; f) procrastinação do contato entre a mãe e o neonato; g) recriminar a parturiente por qualquer característica ou ato físico, tais como: altura, peso, opção sexual, raça, pelos, evacuação, estrias, etc, dentre outras práticas amplamente condenadas pela OMS.

\title{
3 VIOLÊNCIA OBSTÉTRICA: ANÁLISE JURISPRUDENCIAL A PARTIR DOS ACÓRD̃̃OS DO STF E STJ
}

O artigo objetiva analisar a temática da violência obstétrica a partir da análise dos acórdãos do STF e do STJ. Inicialmente foi realizada uma busca exploratória nos sítios eletrônicos dos respectivos tribunais nos meses de outubro e novembro de 2015. Utilizamos inicialmente a palavra "violência obstétrica", sem entretanto encontrar nenhum dado referente a esta palavra chave. Prosseguiu-se a busca eletrônica através das palavras-chave expostas na tabela abaixo, que são associadas a situações que caracterizam a violência obstétrica, sendo encontrados os resultados abaixo arrolados.

Tabela 1 - Quantidade de acórdãos encontrados após pesquisas com palavras-chave 


\begin{tabular}{|c|c|c|}
\hline Palavra-chave & STF & STJ \\
\hline Violência obstétrica & 0 & 0 \\
\hline Episiotomia & 1 & 1 \\
\hline Cesárea lesão & 0 & 0 \\
\hline Lesão no parto & 2 & 17 \\
\hline Manobra de Kristeller & 0 & 1 \\
\hline Erro médico parto & 0 & 30 \\
\hline
\end{tabular}

Fonte: Autoras, 2015

A fim de precisar a escolha dos acórdãos que comporiam a presente amostra, cada julgado encontrado teve seu conteúdo analisado detalhadamente a fim de verificar aqueles que evidenciavam de fato a violência obstétrica, sendo escolhidos os mais expressivos.

O primeiro acórdão analisado foi encontrado através da palavra-chave "episiotomia" no sítio do STF, julgado pela Segunda Turma, sendo o relator Ministro Celso de Mello:

E M E N T A: RESPONSABILIDADE CIVIL OBJETIVA DO PODER PÚBLICO - ELEMENTOS ESTRUTURAIS - PRESSUPOSTOS LEGITIMADORES DA INCIDÊNCIA DO ART. 37, $\S 6^{\circ}$, DA CONSTITUIÇÃO DA REPÚBLICA TEORIA DO RISCO ADMINISTRATIVO - HOSPITAL PÚBLICO QUE INTEGRAVA, À ÉPOCA DO FATO GERADOR DO DEVER DE INDENIZAR, A ESTRUTURA DO MINISTÉRIO DA SAÚDE - RESPONSABILIDADE CIVIL DA PESSOA ESTATAL QUE DECORRE, NA ESPÉCIE, DA INFLIÇÃO DE DANOS CAUSADA A PACIENTE EM RAZÃO DE PRESTAÇÃO DEFICIENTE DE ATIVIDADE MÉDICO-HOSPITALAR DESENVOLVIDA EM HOSPITAL PÚBLICO - LESÃO ESFINCTERIANA OBSTÉTRICA GRAVE - FATO DANOSO PARA A OFENDIDA RESULTANTE DE EPISIOTOMIA REALIZADA DURANTE O PARTO - OMISSÃO DA EOUIPE DE PROFISSIONAIS DA SAÚDE, EM REFERIDO ESTABELECIMENTO HOSPITALAR, NO ACOMPANHAMENTO PÓS-CIRÚRGICO - DANOS MORAIS E MATERIAIS RECONHECIDOS - RESSARCIBILIDADE DOUTRINA - JURISPRUDÊNCIA - RECURSO DE AGRAVO IMPROVIDO. (AI 852237 AgR, Relator(a): Min. CELSO DE MELLO, Segunda Turma, julgado em 25/06/2013, ACÓRDÃO ELETRÔNICO DJe-176 DIVULG 06-09-2013 PUBLIC 09-09-2013, grifo nosso).

Conforme analisado anteriormente, a episiotomia de rotina é considerada uma prática associada a violência obstétrica que pode ocasionar uma série de complicações à parturiente. Sua prática implica em ser computado procedimento adicional além do parto, além de definir mais dias de internação hospitalar, o que acaba gerando mais lucratividade para médicos e instituições hospitalares. Ademais, serve como oportunidade de treinamento prático para os médicos residentes na área.

No acórdão analisado, a episiotomia ocasionou uma lesão esfincteriana grave à paciente, advinda do trauma obstétrico, resultando em incontinência fecal, o que perturbou o 
equilíbrio emocional, social e psicológico da paciente, uma vez que afetou negativamente seu convívio social, restringindo-o. Analisando o inteiro teor do acórdão é possível inferir justamente, o caráter omissivo configurado nas práticas obstétricas de episiotomia e os sintomas dela advindos na vida da parturiente:

\begin{abstract}
As circunstâncias do presente caso evidenciam que o nexo de causalidade material restou plenamente configurado em face do comportamento omissivo em que incidiu o Poder Público, que se absteve de "(...) orientar a autora sobre o procedimento adotado no seu parto, assim como os eventuais riscos a que estaria exposta. como também a necessidade do seu retorno ao hospital para 0 acompanhamento médico de sua situacão. (fls. 329). Lamentavelmente, essa incompreensível omissão estatal foi causa do evento danoso. (...) teve que se afastar de suas atividades laborais, devido a sua incontinência fecal, tendo que se submeter, posteriormente, a um procedimento cirúrgico para a reparacão de seu problema (fls. 328). (AI 852237 AgR, Relator(a): Min. CELSO DE MELLO, Segunda Turma, julgado em 25/06/2013, ACÓRDÃO ELETRÔNICO DJe-176 DIVULG 06-09-2013 PUBLIC 09-09-2013, p. 5-6, grifo nosso).
\end{abstract}

Infelizmente, verifica-se ainda, hipossuficiência técnica por parte dos julgadores para aquilatar devidamente este tipo de violência, uma vez que em suas decisões deixam de contemplar a violência psicológica sofrida pela parturiente nos contextos avaliados e deixam ainda de evidenciar a ocorrência da violência obstétrica. $\mathrm{O}$ caso em questão, por exemplo, limita-se apenas a discutir a responsabilidade civil da administração pública.

O segundo acórdão analisado com indícios de violência obstétrica, foi encontrado na esfera do STJ através da palavra-chave "erro médico parto".

PROCESSUAL CIVIL. AGRAVO REGIMENTAL NO AGRAVO EM RECURSO ESPECIAL. ÓBICES LEVANTADOS PELA DECISÃO DE ADMISSIBILIDADE DO ESPECIAL. INFIRMADOS. ERRO MÉDICO. PARTO OUE CAUSOU SEOUELAS PERMANENTES NA CRIANCA. DEVER DE INDENIZAR. DANOS MORAIS. [...]_(AgRg no AgRg no AGRAVO EM RECURSO ESPECIAL $N^{\circ} 672.584$ - DF. Min. OG Fernandes, Segunda Turma, julgado em 22/10/2015, grifo nosso).

Cumpre frisar que em mais de um acórdão, encontramos a responsabilidade civil por erro médico em decorrência de distócia de ombro do neonato, e em outros casos paralisia cerebral do mesmo. Tais agravantes estão relacionados em alguns casos à utilização da manobra de Kristeller. Analisando na íntegra o julgado supracitado, constatamos que o tribunal de origem decidiu a demanda nos seguintes termos:

No particular, a conduta estatal restou evidenciada pela condução do parto forcado com utilizacão de fórceps e Kristeller, quando possível a adocão de melhores técnicas para preservar a integridade física da crianca, sendo que, em virtude de manobras médicas realizadas, a menor nasceu com sequelas. Registre-se que, inicialmente, o parto seria realizado mediante cesárea, tendo sido alterado para 
aquela modalidade. Note-se, também, que o réu não apresentou qualquer justificativa a respeito da motivação que ensejou a alteração abrupta da modalidade de parto. Ao lado disso, não se pode olvidar que a "manobra de Kristeller. consistente em pressionar manualmente o fundo do útero da parturiente, com 0 objetivo de abreviar o período expulsivo, constitui técnica perigosa e vedada pelo próprio sistema público, conforme Protocolos de Urgência e Emergência da Secretaria de Saúde do Distrito Federal. O dano, por seu turno, também sobressai incontroverso. De acordo com a documentação juntada aos autos, durante o parto da autora ocorreu dificuldades na extracão dos ombros (distócia de ombros) que deu causa à lesão do plexo braquial esquerdo. [...] No particular, ao contrário do que afirmou o réu, o sofrimento. físico e moral decorrente da adocão de procedimentos equivocados verificados durante o trabalho de parto certamente gerou dor irreparável à menor, além. de causar profundo abalamento em sua dignidade e esfera íntima, não existindo, por certo. meios de recompor a situacão ao status quo ante. Com efeito, as sequelas físicas e psicológicas deixadas na oportunidade do seu nascimento e que a acompanharão durante o resto da vida, reduzindo-lhe a qualidade de vida, são capazes de vilipendiar seus atributos da personalidade. Em suma: a integridade física e mental da autora foi frontalmente violada a lhe impingir prejuízo de ordem moral, concernente no abalo psíquico e estético, razão pela qual não merece reparos a r. sentença impugnada que reconheceu seu direito a uma compensação pecuniária a esse título. (AgRg no AgRg no AGRAVO EM RECURSO ESPECIAL N 672.584 - DF. Min. OG Fernandes, Segunda Turma, julgado em 22/10/2015, grifo nosso, p. 2-3).

A manobra de Kristeller, resultante de "pressões inadequadamente aplicadas ao fundo uterino no período expulsivo", constitui-se claramente prejudicial ou ineficaz e deve ser eliminada. (BRASIL, 2001, p. 188). O ministro relator do caso supracitado manteve sua decisão, citando os mesmos fundamentos do Tribunal de origem.

O terceiro acórdão analisado com indícios de violência obstétrica, foi encontrado também no STJ, através da palavra-chave "erro médico parto".

RECURSO ESPECIAL - AÇÃO DE INDENIZAÇÃO - DANOS MORAIS E MATERIAIS - ERRO MÉDICO - MÁ PRESTACÃO DE SERVICOS

$\begin{array}{llllll}\text { HOSPITALARES - } & \text { RETARDAMENTO } & \text { DE } & \text { PARTO } & \text { E }\end{array}$
COMPROMETIMENTO DA SAÚDE DA MÃE E DA MENOR RECÉMNASCIDA [...] (RECURSO ESPECIAL N ${ }^{\circ} 1.195 .656$ - BA (2010/0094662-0). Min. Massami Uyeda, Terceira Turma, julgado em 16/08/2011, grifo nosso).

Esse último julgado mostra-se extremamente interessante para a configuração da violência obstétrica, uma vez que a partir da análise do inteiro teor do acórdão, constatamos que a parturiente sofreu suposto erro médico que ensejou o retardamento do parto causando- lhe lesões corporais, bem como submetendo a filha recém-nascida a "encefalopatia hipóxica isquêmica", ante a prolongada privação de oxigênio, causando-lhe gravíssima lesão cerebral, tida por irreversível, fazendo com que a menor dependa de cuidados médicos especializados por toda a vida. 
O egrégio Tribunal de Justiça da Bahia negou provimento ao recurso de apelação impetrado pelo hospital e pelo médico/recorrente, nos seguintes termos:

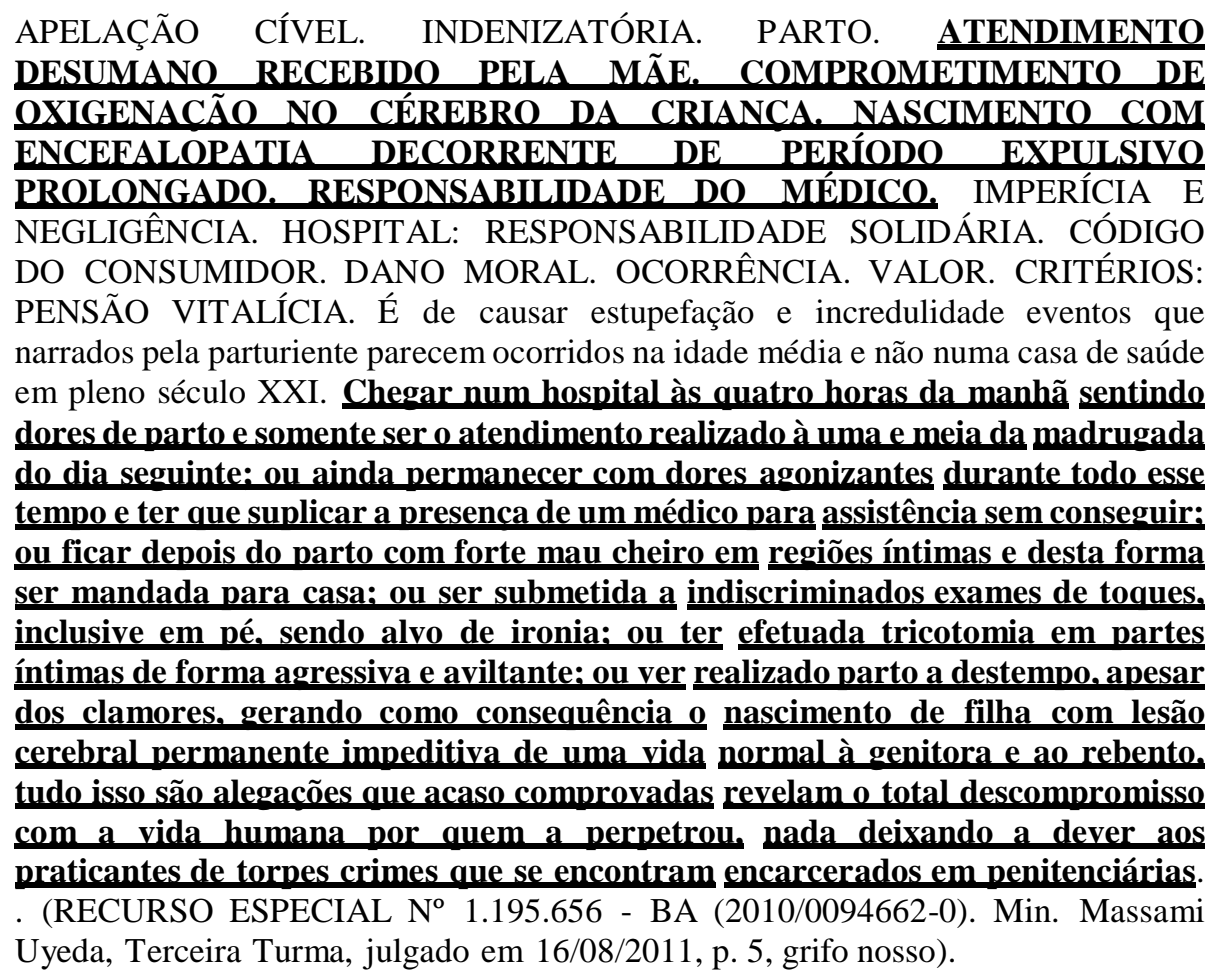

Podemos analisar no caso em tela que houve mais de uma situação caracterizadora da violência obstétrica: demora demasiada no atendimento da parturiente; descaso; excessivos exames de toque; violência psicológica mediante ironia e humilhações; tricotomia agressiva e aviltante, culminando na lesão cerebral da recém-nascida.

Salienta-se, que a ausência de legislação específica não impede que os aplicadores do Direito possam punir a prática, uma vez que resta caracterizada a violação de princípios e direitos basilares do Estado Democrático de Direito, podendo haver a aplicação da responsabilidade civil da equipe hospitalar e do Estado (art. 927 e seguintes do CC/02) ou ainda aplicação da lei penal em caso de constrangimento ilegal (art. 146, CP), lesão corporal (art. 129, CP) ou homicídio (art. 121, CP).

\section{CONSIDERAÇÕES FINAIS}

A partir da análise dos acórdãos, constatamos que a violência obstétrica corresponde a uma forma da violência de gênero específica, tendo em vista que abrange condutas e/ou omissões perpetradas pelos profissionais de saúde no controle do corpo e da sexualidade das mulheres, além de estar dominada por significados culturais estereotipados de desvalorização 
e subserviência. Nesse sentido, faz-se mister ressaltar a importância de que em tais casos, os agentes do sistema de justiça, em especial, a magistratura, busquem analisar tais processos sob uma perspectiva de gênero, conforme preconizado nos tratados internacionais de direitos humanos das mulheres.

A violência obstétrica como forma de violência de gênero deve ser difundida, sobretudo através de seu reconhecimento em decisões judiciais, uma vez que em função da sua condição de intensa vulnerabilidade durante a gestação, cada vez mais mulheres sofrem este tipo de violência, ainda pouco reconhecida. Infelizmente, os julgados sequer mencionam o termo "violência obstétrica", o que favorece a invisibilidade do fenômeno no curso do processo judicial.

Frisa-se que o termo violência obstétrica ainda não é também encontrado em nenhum julgado dos Tribunais de Justiça do Brasil, consoante pesquisa realizada no sítio eletrônico JusBrasil.

Destarte, conforme mencionado anteriormente, isso não significa que a violência obstétrica não esteja associada aos julgados, visto que em análise mais detalhada de decisões das Cortes supremas percebeu-se claramente a modalidade de violência evidenciada sendo empregada contra as parturientes. Nessa esteira, faz-se necessário pleitear a capacitação continuada dos magistrados e demais operadores do direito para que possam compreender melhor a temática e assim aprofundar seus conhecimentos a fim de que sejam proferidas decisões melhor embasadas tecnicamente e com as sanções devidas à gravidade dos casos trazidos em juízo.

Percebe-se ainda a necessidade de divulgação do tema por meio de políticas públicas de prevenção, bem como a necessidade de conscientização da população em geral acerca do parto humanizado, para que as parturientes possam efetivamente reconhecer e passar a pleitear seus direitos, pois, infelizmente, o número expressivo de mulheres que sofrem violência obstétrica ainda não pode ser mensurado através dos casos que chegam aos tribunais.

Ademais, a problemática carece de leis e diretrizes para assegurar uma assistência humanizada no momento do parto, cabendo, portanto, aos entes estatais, a elaboração de leis específicas. Insta ainda salientar, a importância na capacitação dos profissionais da área de saúde que contemple uma visão social e humanística, de modo a oferecer à parturiente um processo de atenção adequado no ciclo gravídico-puerperal.

Entretanto, embora inexpressiva a quantidade de acórdãos relacionados ao tema na esfera do STF, o caso encontrado, já é um importante julgado sobre uma das práticas mais 
veementes e comuns de violência obstétrica: a episiotomia. A Corte já se posicionou no sentido de que cabe responsabilização do poder público e também do médico, não podendo generalizar a responsabilização nos casos justificados e emergenciais.

Entretanto, os julgados ainda permanecem silentes diante da amplitude do panorama iatrogênico da violência obstétrica. Apesar da possibilidade de imputação da responsabilidade civil aos executores, bem como das devidas indenizações às vítimas, há ainda a difícil tarefa em comprovar o nexo de causalidade entre a conduta médico-hospitalar e o dano. Ademais, as autoras dos processos, desejam, de fato, que seja reconhecida judicialmente a violência praticada por tais agentes, não simplesmente como erro médico, como foi possível perceber na maioria dos acórdãos analisados, mas sim como violência de gênero, especificando claramente a violência obstétrica.

\section{REFERÊNCIAS}

AGUIAR, Janaína Marques de. Violência institucional em maternidades públicas: hostilidade ao invés de acolhimento como uma questão de gênero. Disponível em: <http://www.apublica.org/wp-content/uploads/2013/03/JanainaMAguiar.pdf>. Acesso em: 02 nov. 2015.

ALEXANDRE, Sandra Maria et al. Episiotomia: revendo conceitos. Femina, Rio de Janeiro, v. 37, n. 7, p. 367-371, jul. 2009.

ARGENTINA. Ley 26.485, de 11 de marzo de 2009. Ley de protección integral para prevenir, sancionar y erradicar la violencia contra las mujeres en los ámbitos en que desarrollen sus relaciones interpersonales. Disponível em: <http://www.osim.com.ar/ osim/alzalavoz/Ley_de_Proteccion_Integral_de_Mujeres_Argentina.pdf $>$. Acesso em: 02 nov. 2015.

BRASIL. Agência Nacional de Saúde Suplementar. O modelo de atenção obstétrica no setor de Saúde Suplementar no Brasil: cenários e perspectivas. Rio de Janeiro: ANS, 2008.

Agência Nacional de Vigilância Sanitária. Resolução da Diretoria Colegiada - RDC $\mathrm{n}^{\circ}$ 36, de 3 de junho de 2008. Dispõe sobre Regulamento Técnico para Funcionamento dos Serviços de Atenção Obstétrica e Neonatal. Brasília: AVISA, 2008.

Decreto $n^{0}$ 1.256, de 29 de setembro de 1994. Promulga a Convenção

Interamericana para Prevenir, Punir e Erradicar a Violência contra a Mulher, concluída em Belém do Pará, em 9 de junho de 1994. Diário Oficial da União, Brasília, DF, 2 ago. 1996. Seção 1, p. 15.

Defensoria Pública do Estado de São Paulo. Violência obstétrica: você sabe o que é?. Escola da Defensoria Pública do Estado: São Paulo, 2013. Disponível em: <http://www. defensoria.sp.gov.br/dpesp/repositorio/41/violencia\%20 obstetrica.pdf>. Acesso em: 10 dez. 2015. 
Ministério da Saúde. Humanização do parto e do nascimento. Caderno HumanizaSUS, v. 4. Brasília: Ministério da Saúde, 2014.

Ministério da Saúde, Secretaria de Políticas de Saúde, Área Técnica de Saúde da Mulher. Parto, aborto e puerpério: assistência humanizada à mulher. Brasília: Ministério da Saúde, 2011.

Organização Mundial de Saúde. Declaração da OMS sobre Taxas de Cesáreas. 2015. Disponível em: <http://apps.who.int/iris/bitstream/10665/161442/3/ WHO_RHR_15.02 _por.pdf>. Acesso em: 04 nov. 2015.

Organização Mundial de Saúde. Prevenção e eliminação de abusos, desrespeito e maus-tratos durante o parto em instituições de saúde. 2014. Disponível em: <http://apps. who.int/iris/bitstream/10665/134588/3/WHO_RHR_14.23_por.pdf>. Acesso em: 04 nov. 2015.

.SUPREMO TRIBUNAL FEDERAL. AI 852237 AgR. Relator(a): Min. Celso de Mello. Brasília, DF, 09 de setembro de 2013. Disponível em: < http://redir.stf.jus.br/ paginadorpub/paginador.jsp?docTP=TP\&docID=4463295>. Acesso em: 27 out. 2015.

.SUPERIOR TRIBUNAL DE JUSTIÇA. AgRg no AgRg no AGRAVO EM RECURSO ESPECIAL No 672.584 - DF (2015/0046418-0). Relator(a): Min. OG Fernandes. Brasília, DF, 22 de setembro de 2015. Disponível em: < https://ww2.stj.jus.br/ processo/revista/documento/mediado/?componente=ATC\&sequencial $=51595403 \&$ num_regis tro $=201500464180 \&$ data $=20151007 \&$ tipo $=5 \&$ formato=PDF $>$. Acesso em: 27 out. 2015.

.SUPERIOR TRIBUNAL DE JUSTIÇA. RECURSO ESPECIAL No 1.195.656 - BA (2010/0094662-0). Relator(a): Min. Massami Uyeda. Brasília, DF, 09 de agosto de 2011. Disponível em: < https://ww2.stj.jus.br/processo/revista/documento/mediado/?componente= ATC\&sequencial $=16008763 \&$ num_registro $=201000946620 \&$ data $=20110830 \&$ tipo $=91 \&$ for mato $=$ PDF $>$. Acesso em: 27 out. 2015.

COSTA, Nilma Maia da et al. Episiotomia nos partos normais: uma revisão de literatura. FACENE, João Pessoa, p. 45-50, 2011. Disponível em: < http://www. facene.com.br/wpcontent/uploads/2010/11/2011-2-pag-45-50-Episiotomia.pdf > . Acesso em: 27 out. 2015.

DINIZ, Carmen Simone Grilo. Entre a técnica e os direitos humanos: possibilidades e limites das propostas de humanização do parto. Tese de doutorado. Faculdade de Medicina/ USP, São Paulo.

DINIZ, Simone Carmen Grilo. Campanha pela abolição da episiotomia de rotina. 2003. Disponível em: <http://www.amigasdoparto.com.br/episiotomia3.html>. Acesso em: 10 dez. 2015.

DIP, Andrea. Na hora de fazer não gritou. Agência de Reportagem e Jornalismo Investigativo. Disponível em: < http://apublica.org/2013/03/na-hora-de-fazer-nao-gritou/>. Acesso em: 11 dez. 2015.

FONEITE, Josmery; FEO, Alejandra; MERLO, Judith Toro. Grado de conocimiento de violencia obstétrica por el personal de salud. Revista de Obstetricia y Ginecología de 
Venezuela. v. 72, n.1, Caracas: março, 2012. Disponível em: <http:// www.scielo.org.ve/ scielo.php?script=sci_arttext\&pid=S0048-77322012000100002\&lng=es\&nrm=iso\&tlng=es $>$. Acesso em: 02 nov. 2015.

MAIA, Mônica Bara. Humanização do parto: política pública, comportamento organizacional e ethos profissional. Rio de Janeiro: Fiocruz, 2008. Disponível em: <http:// www.biblioteca.pucminas.br/teses/CiencSociais_MaiaMB_1.pdf>. Acesso em: 13 out. 2015.

MOROSINI, Liseane. Nascer é normal! Escola Nacional de Saúde Pública Sergio Aroucha. Disponível em: <http://www6.ensp.fiocruz.br/radis/revista-radis/143/reportagens/nascer-enormal>. Acesso em: 11 dez. 2015.

PARTO DO PRINCÍPIO. Dossiê da Violência Obstétrica "Parirás com dor". 2012.

Disponível em: <http://www.senado.gov.br/comissoes/documentos/SSCEPI/DOC\%20VCM\% 20367.pdf>. Acesso em: 10 dez. 2015.

POMPEO, Carolina. Uma em cada quatro mulheres sofre violência obstétrica no Brasil. Gazeta do Povo. Disponível em: http://www.gazetadopovo.com.br/vida-e-cidadania/uma-emcada-quatro-mulheres-sofre-violencia-obstetrica-no-brasil-ee5jkxiutgeb18bwkud2ozhhq>. Acesso em: 11 dez. 2015.

PREVIATTI, Jaqueline Fátima; SOUZA, Kleyde Ventura de. Episiotomia: em foco a visão das mulheres. Revista Brasileira de Enfermagem, Brasília, v. 60, n. 2, p. 197-201, mar./abr. 2007.

TORRE, Luísa. Humilhação e violência na hora do parto. Gazeta Online. Disponível em: <http://www.gazetaonline.com.br/_conteudo/2014/06/noticias/cidades/1490289-humilhacaoe-violencia-na-hora-do-parto.html>. Acesso em: 10 dez. 2015.

Violência obstétrica é violência contra mulher: mulheres em luta pela abolição da violência obstétrica. 1. ed. São Paulo: Parto do princípio; Espírito Santo: Fórum de Mulheres de Espírito Santo, 2014.

WARMIS. Manobra de Kristeller - Violência no parto. Disponível em: http://www.warmismulheresbolivianas.com.br/blog/manobra-de-kristeller-violencia-noparto/>. Acesso em: $10 \mathrm{dez} .2015$. 